\title{
MIGRAÇÃO, GLOBALIZAÇÃO E RELAÇÕES INTERNACIONAIS: EM BUSCA DE NOVAS INTERPRETAÇÕES FUNDAMENTADAS EM EVIDENCIAS LATINO- AMERICANAS RECENTES
}

\author{
Carlos Frederico Domínguez Avila*
}

\begin{abstract}
Resumo
O propósito deste estudo é compreender, avaliar e propor novas interpretações sobre o fenômeno da migração internacional, em geral, e da migração latino-americana, em particular, a partir de evidencia documental recente. Ao analisar especificamente o caso das tendências migratórias na América Latina e Caribe é bastante claro que o fenômeno se transformou em tema de grande relevância na agenda hemisférica e global. Segundo estimativas recentes, aproximadamente 40 milhões de latino-americanos e caribenhos moram fora dos seus paises de origem. Outrossim, existem boas razões para prever que a migração internacional, em geral, e a migração latinoamericana e caribenha, em particular, continuarão sendo fenômenos importantes nas relações internacionais nas próximas décadas. Este expressivo fluxo migratório no sentido Sul-Norte é impulsionado por dois importantes conjuntos de motivos. De um lado, as profundas diferenças econômicas internacionais e as agudas insuficiências estruturais dos países em desenvolvimento favorecem a opção de procurar novos horizontes em outros países, regiões e continentes. De outro, é cada vez mais evidente que os países capitalistas avançados - porém demograficamente envelhecidos - precisam de uma força de trabalho jovem, qualificada e certamente estrangeira, inclusive para manter seus altos padrões de consumo e renda. Portanto, trata-se de alcançar um novo equilíbrio na procura e demanda de força de trabalho, no contexto geral do processo de globalização.
\end{abstract}

Palavras-chaves: Migração; Globalização; Relações Internacionais; América Latina e Caribe.

\section{Introdução}

A migração internacional é uma das manifestações mais diretas, evidentes e expressivas da atual fase do assim chamado processo de globalização. Aproximadamente 175 milhões de pessoas residem em nações diferentes do país de origem - isto é, habitam em algum país receptor de imigrantes. Note-se que por volta de 40 milhões daqueles migrantes nasceram ou são descendentes de famílias procedentes de algum país da América Latina e Caribe. Conseqüentemente, trata-se de um fenômeno de alcance global, complexo, e altamente significativo.

Inicialmente, parece importante reconhecer que a noção de migração implica o movimento de pessoas - isto é, seu deslocamento geográfico temporário

\footnotetext{
* Doutor em história das relações internacionais pela Universidade de Brasília (2003). Professor do UniCEUB.
} 
ou definitivo. O conjunto de motivações ou incentivos que historicamente impulsionaram as migrações é bastante numeroso, incluindo, por exemplo: a aspiração de melhorar as condições de vida e de emprego (educação, saúde, etc.), os deslocamentos forçosos para preservar a integridade física (normalmente provocados por conflitos armados domésticos e internacionais), as desigualdades nos níveis de desenvolvimento, as assimetrias na distribuição dos benefícios oferecidos pela economia internacional, as carências de capital humano e conhecimentos, a curiosidade, dentre outros. Note-se, ainda, que o termo migrante não se limita aos deslocamentos de trabalhadores e profissionais (qualificados ou não). Outros indivíduos, tais como refugiados, turistas e estudantes, também podem ser estudados a partir desta categoria. Tudo isso sem esquecer as convergências ou sinergias reais ou potenciais que surgem entre os chamados pull e push effects, isto é, as pressões migratórias endógenas e exógenas geradas pelo mundo atual, tanto nas economias desenvolvidas como nas economias em desenvolvimento.

Ainda que a migração humana é uma das formas mais óbvias de globalização, não existe uma consistente tradição de pesquisa deste fenômeno sob a perspectiva da disciplina Relações Internacionais. Trata-se de um objeto de estudo que não tem chamado a atenção dos principais pesquisadores desta comunidade acadêmica. Curiosamente, a temática tem recebido maior atenção de disciplinas como a demografia que da própria disciplina relações internacionais teoricamente a disciplina encarregada de estudar este tipo de fenômenos, às vezes chamados de "intermésticos". Contudo, nos últimos anos o fenômeno da migração internacional adquiriu tal relevância na América Latina e Caribe que certos especialistas das relações internacionais passaram a estuda-lo com propósito de oferecer novas idéias e interpretações úteis e plausíveis no momento de formular e implementar políticas específicas - ou simplesmente para reagir frente às realidades, desafios e oportunidades colocados pelo fenômeno em questão. ${ }^{1}$ 


\section{A migração internacional no contexto da atual fase de globalização}

O fluxo migratório contemporâneo apresenta uma conotação massiva. Segundo relatórios das Nações Unidas, o número de pessoas que participam diretamente de tais correntes migratórias internacionais cresceu consideravelmente durante a segunda metade do século XX. Atualmente, por volta de 175 milhões de pessoas residem em países diferentes ao do nascimento. A Europa Ocidental, os Estados Unidos e certos países de Oceania - especialmente o caso da Austrália - são os principais destinos dos migrantes internacionais.

Conseqüentemente, o impacto geral dos processos ou fluxos migratórios é alto e crescente, tanto nos países de origem (ou emissores), quanto nos países de destino (ou receptores) e de trânsito (ou de passagem).

Paralelamente, parece importante ressaltar que em outras fases do processo de globalização - levando-se em consideração que o processo de globalização apresenta antecedentes bastante antigos (Held e outros, 1999; CEPAL, 2002) - os deslocamentos de população acompanharam de perto o desenvolvimento de contatos e fluxos de capitais, comércio, tecnologias e valores. $\mathrm{Na}$ atual fase do processo de globalização, porém, a mobilidade das pessoas enfrenta fortes barreiras que a restringem, especialmente quando se trata de migrações de pessoas pouco qualificadas com destino a países do centro do capitalismo. Assim, muitos autores questionam 0 fato de que a migração internacional parece estar excluída da nova fase do processo de globalização. A globalização sem ou com pouca migração internacional levanta muitas dúvidas com relação aos seus fundamentos éticos, ao realismo político e à eficiência econômica.

Convém acrescentar que o fenômeno migratório internacional especialmente no sentido Sul-Norte - também deve ser abordado tanto pelo lado da oferta de força de trabalho (ou push effect), quanto pelo lado da demanda de força de trabalho (ou pull effect). De modo geral, o push effect que impulsiona a migração internacional no sentido Sul-Norte vincula-se com realidades sociais, políticas e econômicas imperantes nos países em desenvolvimento que agem no 
sentido de "expulsar" ou "empurrar para fora" a população com condições reais ou potenciais para migrar. Assim, a oferta de força de trabalho oriunda de países em desenvolvimento surge de pressões e forças profundas reais que incluem, por exemplo, a exclusão social, o desemprego, a crise ambiental global, conflitos armados internos, a universalização das aspirações de consumo e bem-estar, meios de transporte cada vez mais rápidos, seguros e baratos (especialmente o transporte aéreo), dentre outros.

De modo complementar, a evolução recente dos países do centro do capitalismo, especialmente no caso dos países europeus, demonstra uma crescente necessidade de importar força de trabalho oriunda dos países em desenvolvimento. Assim, o pull effect surge de fenômenos tais como a chamada "segunda transição demográfica" ou acelerado envelhecimento da estrutura da população, o alto e crescente déficit no número de pessoas em idade produtiva que ingressam aos mercados de trabalho, o crescente desequilíbrio entre a população ativa e passiva - com impacto direto nos sistemas de previdência e seguridade social -, as facilidades nas comunicações internacionais cada vez mais rápidas, seguras e baratas (Internet, etc.), dentre outros. Neste sentido, parece evidente que para manter o alto e dispendioso padrão de consumo e de vida, as sociedades capitalistas centrais precisam - objetivamente - de força de trabalho qualificada e não-qualificada oriunda de países em desenvolvimento.

Em suma, tudo faz prever que a migração internacional no sentido SulNorte continuará sendo um fenômeno importante nas relações internacionais nas próximas décadas. De um lado, as profundas diferenças econômicas internacionais e as agudas insuficiências estruturais dos países em desenvolvimento favorecem a opção de procurar novos horizontes em outros países, regiões e continentes. Entretanto, é cada vez mais evidente que os países capitalistas avançados - porém demograficamente envelhecidos - precisam de uma força de trabalho jovem, qualificada (e não qualificada) e certamente estrangeira. Todavia, é bem provável que as autoridades de tais países, especialmente no caso dos europeus, fortalecerão as estratégias que tendem a atrair recursos humanos qualificados e manterão a demanda de recursos 
humanos menos qualificados para realizarem tarefas que os seus nacionais não mais desejam cumprir, especialmente em atividades de pouco prestígio social e muitas vezes mal remuneradas. Portanto, trata-se de alcançar um novo equilíbrio na procura e demanda de força de trabalho, no contexto geral do processo de globalização.

Outrossim, vale destacar que para estudar as migrações internacionais no marco geral do processo de globalização é possível e pertinente utilizar variáveis tais como: (a) a extensão ou abrangência dos fluxos migratórios, (b) a intensidade, (c) a velocidade dos deslocamentos, (d) seu impacto nas comunidades de origem, trânsito e destino, (e) a infraestrutura disponível (especialmente no que diz respeito à estrutura de transporte, comunicações, e regulamentações). Uma primeira aproximação do problema-objeto com base em tais variáveis é a tabela a seguir.

Tabela 1: Principais características do padrão contemporâneo de migração internacional (1970-2000)

\begin{tabular}{|c|c|}
\hline Variável & Características gerais \\
\hline $\begin{array}{l}\text { Principais fluxos } \\
\text { migratórios na atual } \\
\text { fase do processo de } \\
\text { globalização }\end{array}$ & $\begin{array}{l}\text { A partir das décadas de } 1970 \text { e } 1980 \text { o principal fluxo } \\
\text { migratório global passa a ser no sentido Sul-Norte. Isto é, } \\
\text { com destino à América do Norte, Europa Ocidental e } \\
\text { Austrália. Os países produtores de petróleo do golfo } \\
\text { Pérsico também recebem importante fluxo migratório } \\
\text { regional e global. Subsistem pequenos fluxos migratórios } \\
\text { nos sentidos Norte-Norte, Sul-Sul e Norte-Sul. } \\
\text { Crescente relevância da migração de técnicos e } \\
\text { profissionais altamente qualificados. Bem como de } \\
\text { migrantes sem documentação, trabalhadores pouco } \\
\text { qualificados profissionalmente, refugiados, turistas, dentre } \\
\text { outros. }\end{array}$ \\
\hline $\begin{array}{l}\text { Extensão } \\
\text { abrangência }\end{array}$ & $\begin{array}{l}\text { Principais fluxos globais com destino a: Europa } \\
\text { Ocidental, América do Norte, Austrália e golfo Pérsico, } \\
\text { Fluxos migratórios intra-regionais na Árica } \\
\text { (especialmente na Nigéria, África do Sul e Líbia), sudeste } \\
\text { asiático (Cingapura, Japão, Malásia, Tailândia, e outros } \\
\text { "tigres") e América Latina (Argentina, Venezuela e } \\
\text { México). } \\
\text { Fluxos menores ou binacionais. }\end{array}$ \\
\hline
\end{tabular}




\begin{tabular}{|l|l|}
\hline Intensidade & $\begin{array}{l}\text { Comparado com outros períodos históricos, os fluxos } \\
\text { migratórios contemporâneos podem ser considerados de } \\
\text { mediana intensidade, ainda que com tendência crescente. }\end{array}$ \\
\hline Velocidade & $\begin{array}{l}\text { É muito alta a velocidade dos deslocamentos individuais } \\
\text { e coletivos. Predominância do transporte aéreo } \\
\text { internacional. }\end{array}$ \\
\hline Institucionalização & $\begin{array}{l}\text { Alta institucionalização dos sistemas de transporte e } \\
\text { comunicações, controle das fronteiras, e mercados de } \\
\text { trabalho. } \\
\text { Crescimento da migração irregular (sem documentos). } \\
\text { Considerável incremento da vigilância e disciplinamento } \\
\text { dos fluxos (especialmente no sentido Sul-Norte). }\end{array}$ \\
\hline $\begin{array}{l}\text { Parece necessário distinguir entre os migrantes } \\
\text { altamente qualificados (ou migrantes de elite, com muitas } \\
\text { opções e facilidades nos países de destino) e os migrantes } \\
\text { pouco qualificados, refugiados, asilados, etc. (ou } \\
\text { migrantes de massa, com poucas facilidades e opções nos } \\
\text { países de destino). }\end{array}$ \\
\hline
\end{tabular}

\section{Grandes tendências da migração internacional na América Latina e Caribe}

O deslocamento transitório ou definitivo de pessoas tem constituído uma característica essencial na história econômica, política e social da América Latina e Caribe. De fato, a América é literalmente um continente de imigrantes e seus descendentes.

Desde a chegada dos primeiros habitantes do continente aproximadamente 30 mil anos antes de Cristo - até os atuais fluxos migratórios Sul-Norte, é possível estudar o fenômeno migratório em cinco grandes fases:

- $\quad$ As grandes ondas pré-colombianas, lembrando que os primeiros habitantes da América foram polinésios, mongóis e possivelmente africanos, e que em 1492 o continente era habitado por aproximadamente 70 milhões de pessoas;

- Ondas migratórias do período colonial, caracterizadas pela imigração de colonizadores europeus e escravos africanos, e pela intensa mestiçagem da população; 
- $\quad$ Segunda onda de imigração européia, complementada com importantes fluxos asiáticos (japoneses, chineses e árabes) durante o século XIX e princípios do século XX;

- Grandes fluxos domésticos no marco do processo de desenvolvimento para dentro, complementados com certas experiências migratórias fronteiriças (mexicanos nos Estados Unidos durante e após a Segunda Guerra Mundial) e certas correntes entre países latino-americanos (especialmente com destino à Argentina e Venezuela);

- Os atuais fluxos migratórios, predominantemente no sentido Sul-Norte, sendo que esta fase merece de uma análise mais cuidadosa e detalhada.

Durante a maior parte da sua história a América Latina foi uma região receptora de imigrantes europeus, asiáticos e africanos. No entanto, a partir do decênio de 1970 o subcontinente se converteu em emissor de população, basicamente com destino aos Estados Unidos e outros países do centro do capitalismo mundial. Esta significativa mudança no padrão migratório latinoamericano não deixou de provocar profundas conseqüências de natureza econômica, social, política, cultural e, de modo geral, nas relações internacionais dado seu impacto nos países de origem, de destino e de trânsito.

Ao analisar especificamente o caso das tendências migratórias na América Latina e Caribe é bastante claro que a migração internacional se transformou em um tema de grande relevância na agenda hemisférica e global destes países. Segundo estimativas recentes do Centro Latino-Americano de Demografia (CELADE), da Comissão Econômica para América Latina e Caribe (CEPAL) e do Sistema Econômico Latino-Americano (SELA), atualmente por volta de 40 milhões de latino-americanos e descendentes residem fora dos seus países de origem. $\mathrm{O}$ México, os países da América Central e os países andinos são os principais emissores de migrantes - no entanto outros países da América do Sul, inclusive o Brasil, também são importantes emissores.

Os principais receptores ou destinos destes migrantes são os Estados Unidos, certos países da Europa Ocidental (especialmente o Reino Unido, a 
França, a Itália, a Espanha e Portugal), bem como outros países da região (especialmente a Argentina, a Venezuela e o México). ${ }^{2}$ Adicionalmente, o México e os países da América Central também são considerados nações de trânsito utilizadas pelos migrantes que se dirigem para o "norte".

A massiva migração latino-americana com destino aos Estados Unidos é um fenômeno relativamente recente. ${ }^{3}$ Segundo estatísticas estadunidenses, a população latino-americana reconhecida passou de pouco menos de um milhão de pessoas em 1960 a 14,5 milhões em 2000. Todavia, a estes dados é necessário acrescentar um importante número de imigrantes sem documentação, refugiados políticos e "retornados" - isto é, descendentes que conseguem ganhar a cidadania estadunidense e retornam ao país dos antepassados como cidadãos reconhecidos. Conseqüentemente, o número total de emigrantes latinoamericanos que vivem nos Estados Unidos pode chegar aos 40 milhões de pessoas. $^{4}$

$\mathrm{Na}$ distribuição da população latino-americana residente nos Estados Unidos, a comunidade mexicana é claramente majoritária. As comunidades de migrantes cubanos, salvadorenhos, brasileiros, colombianos e venezuelanos também são expressivas. Entre 1990 e 2000, as comunidades de imigrantes com maiores taxas de crescimento foram as dos uruguaios, venezuelanos e hondurenhos. ${ }^{5}$

No que diz respeito ao perfil educacional e ocupacional dos migrantes parece claro que o atual padrão migratório latino-americano está constituído por pessoas que podem ser identificadas segundo dois grandes tipos: os pouco qualificados e com baixo nível de escolaridade, e os altamente qualificados e com alto nível de escolaridade.

De fato é possível constatar a existência de um importante grupo de migrantes latino-americanos com baixa qualificação profissional e baixo nível de escolaridade. Em outras palavras, migrantes com baixo capital educacional. Estes migrantes normalmente trabalham em atividades agrícolas, na construção civil, e nos serviços domésticos. Trata-se de atividades de pouco prestígio social e com 
remunerações relativamente baixas. Este tipo de migração é predominante nas comunidades mexicana e centro-americana nos Estados Unidos, bem como nas comunidades equatoriana, brasileira e peruana nos países europeus.

Complementarmente, existe um grupo de migrantes altamente qualificados. Trata-se de profissionais, técnicos, científicos e operários especializados - alguns destes com um capital educacional superior à media dos nativos do país de destino. De modo geral, os emigrantes altamente qualificados se integram em ocupações de alta gerencia empresarial, no mundo acadêmico e nas atividades culturais - isto é, ocupações bem remuneradas e com alto prestígio social. Atualmente mais de 300 mil profissionais e técnicos latino-americanos vivem fora dos países de origem - especialmente nos Estados Unidos. O número de migrantes com alto capital educacional é particularmente relevante no caso das diásporas oriundas da Argentina, da Venezuela e do Chile.

Finalmente, convém acrescentar que as pessoas migram levando os seus padrões culturais. Isso resulta, muitas vezes, numa situação de novas relações sócio-culturais e com a possibilidade de fricção interétnica entre a comunidade migrante e a sociedade receptora. Muitas vezes a presença de uma comunidade étnica gera uma situação de comparação e contraste com a sociedade receptora, particularmente no que diz respeito a valores, costumes e crenças religiosas. Fenômenos sociais tais como o racismo, a xenofobia e a discriminação no mundo do trabalho também podem vincular-se com tais condutas.

No caso do impacto da migração internacional latino-americana, especialmente com destino aos Estados Unidos e Europa Ocidental, os resultados são contraditórios. No caso dos Estados Unidos, a presença social, política, econômica e cultural da comunidade latino-americana é bastante evidente, alta e crescente. A língua espanhola é a segunda mais importante neste país. ${ }^{6} \mathrm{~A}$ arte, o esporte e outras expressões culturais latino-americanas são mundialmente reconhecidos. Atualmente, a soma da riqueza administrada pela comunidade "latina" residente nos Estados Unidos seria pouco menor que o produto interno bruto do Brasil. Outrossim, o voto hispânico é cada vez mais importante em certos 
Estados da União Americana (especialmente em Califórnia, Texas, Florida, Nova York e Arizona). Contudo, a participação política, os ingressos reais e os índices de desenvolvimento social das diásporas latino-americanas ainda apresentam resultados desfavoráveis - quando comparados com a média da população nativa dos países receptores, e sem esquecer que as conseqüências da migração latinoamericana nos países emissores são bastante significativas e duradouras.

\section{O impacto da migração no desenvolvimento e nas relações internacionais da} América Latina: custos, desafios e oportunidades

O expressivo fenômeno da migração latino-americana e caribenha implica custos, desafios e oportunidades nos países emissores, receptores e de trânsito.

Dentre os custos derivados da migração latino-americana e caribenha, especialmente nos países de origem ou emissores, destacam: a desintegração familiar, a chamada "fuga dos cérebros" (isto é, a perda do escasso recurso humano qualificado), e as dificuldades e incertezas surgidas dos deslocamentos internacionais e da adaptação à cultura dominante nas comunidades de destino ou receptoras (bem como aos novos ambientes de trabalho). Quando se trata de pessoas sem documentação ou irregulares os custos psicológicos e sociais são bem maiores, muitas vezes incluindo a vulnerabilidade e o temor perante a possibilidade da detenção e deportação, abusos de autoridades, discriminação, humilhações e outras violações aos seus direitos humanos.

Dentre os desafios colocados aos países emissores, receptores e de trânsito pelo fenômeno migratório latino-americano e caribenho certamente ressaltam: (a) fomentar um fluxo migratório ordenado, legal, disciplinado e congruente com a soberania, a integridade e os interesses nacionais de cada país, (b) lutar contra as atividades delitivas vinculadas ao tráfico de pessoas e os abusos contra os direitos humanos dos migrantes, (c) colocar o debate sobre a migração internacional como prioridade da agenda hemisférica nos primeiros anos do século XXI, (d) promover uma circulação e intercâmbio de recursos humanos qualificados entre os países do continente, procurando diminuir e modificar o 
impacto da chamada "fuga dos cérebros", (e) repensar e avançar em áreas vinculadas ao fenômeno da migração, tais como o trânsito nas fronteiras, a previdência social dos migrantes, o reconhecimento de estudos e qualificações profissionais, a facilitação e redução do custo das transferências financeiras (ou remessas) enviadas pelos migrantes aos seus familiares nos países de origem, e (f) em geral, assegurar a preservação dos direitos humanos dos migrantes e seus descendentes.

No que diz respeito às oportunidades derivadas do fenômeno migratório latino-americano e caribenho cumpre citar as seguintes: (a) a migração permite abrir novos espaços de diálogo, de aproximação e de integração social, econômica e política entre os países, sociedades e culturas do continente e do mundo; (b) a criação de comunidades transnacionais permitiria manter uma identidade familiar, psicológica, cultural e sociopolítica que é sumamente importante para evitar a alienação ou riscos conexos, (c) as remessas ou transferências financeiras enviadas pelos migrantes latino-americanos e caribenhos aos seus familiares nos países de origem - que em 2003 representaram por volta de EUA $\$ 38$ bilhões - é uma fonte de renda extremamente relevante em muitos países, conseqüentemente os Estados poderiam facilitar 0 ingresso de tais recursos, bem como promover modos mais eficientes de utilização no consumo, na poupança e no investimento produtivo (veja-se Tabela 2), (d) o fato de que a comunidade latino-americana e caribenha residente nos Estados Unidos é cada vez mais relevante na política, na cultura e na economia doméstica da principal potencia mundial deve ser considerado de maneira mais enfática, detalhada e profunda no momento de formular e implementar as políticas externas continentais e globais dos países da região, (e) historicamente a migração internacional foi utilizada como uma virtual "válvula de escape" ao permitir uma certa descompressão das tensões geradas pelo desemprego e pela exclusão social nos países de origem, (f) todavia, a migração internacional se erige em uma forma legítima de mobilidade social ascendente. 
Tabela 2: Principais países receptores de remessas na América Latina e Caribe, 2003 (bilhões de dólares dos Estados Unidos)

\begin{tabular}{|l|r|}
\hline México & 13,226 \\
\hline Brasil & 5,200 \\
\hline Colômbia & 3,067 \\
\hline El Salvador & 2,316 \\
\hline República Dominicana & 2,217 \\
\hline Outros 17 países & 11,981 \\
\hline & \\
\hline Total: & 38,047 \\
\hline
\end{tabular}

Fonte: SELA (2004).

Conseqüentemente, e seguindo as ponderações de Adela Pellegrino (2003: 27), parece evidente que "a migração não constitui em si mesma um instrumento de desenvolvimento, mas um mecanismo que pode converter-se tanto em um estímulo para aquelas regiões que experimentam transformações dinâmicas da sua economia como em um fator de descompressão das tensões geradas pelo desemprego. Do mesmo modo, a emigração pode contribuir a gerar um estado de ânimo pessimista e negativo com respeito às possibilidades de desenvolvimento futuro do país e - na medida em que opera quase exclusivamente na população jovem - pode converter-se numa sangria que tira dinamismo e energia aos projetos inovadores."

\section{Tendências futuras da migração internacional latino-americana}

A cada ano, pouco mais de um milhão de latino-americanos e caribenhos decide - por diferentes motivos e razões - abandonar o seu país de origem, procurar novos horizontes e fazer a vida em outros lugares. Conseqüentemente, o fluxo migratório para o "norte" parece inexorável, persistente e duradouro. Assim, existem boas razões para supor que a migração internacional desde América Latina virou fenômeno estrutural e com alta e crescente incidência na agenda doméstica e internacional dos países da região.

Cumpre insistir ou reiterar que a migração latino-americana no sentido SulNorte é impulsionada por motivos e justificativas igualmente coerentes, legítimas e 
concretas - isto é, os push e pull effects. De um lado, as profundas diferenças econômicas internacionais e as agudas insuficiências estruturais dos países em desenvolvimento favorecem a opção de procurar novos horizontes em outros países, regiões e continentes. Entretanto, é cada vez mais evidente que os países capitalistas avançados - porém demograficamente envelhecidos - precisam de uma força de trabalho jovem, qualificada e certamente estrangeira, inclusive para manter seus altos padrões de consumo e renda.

$\mathrm{Na}$ medida que estas constatações objetivas sigam vigentes, é bem provável que o fluxo migratório latino-americano no sentido Sul-Norte continue com uma magnitude semelhante nos próximos anos. Em outras palavras, tudo leva a prever que a migração internacional, em geral, e a migração latinoamericana e caribenha, em particular, continuarão sendo fenômenos importantes na vida das pessoas, das famílias e das sociedades nas próximas décadas.

Nessa hipótese as principais autoridades dos países de origem, de destino e de trânsito terão que se preparar e repensar algumas das suas aproximações teóricas, práticas e políticas vinculadas à questão migratória, procurando favorecer o desenvolvimento de fluxos migratórios ordenados, regulares, seguros e vantajosos para todas as partes.

Ainda que a melhor opção de política pública é oferecer à população de cada país condições de vida e de trabalho satisfatórias e que desencorajem a opção migratória, parece evidente que as atuais circunstancias demandam das autoridades avanços significativos no campo da governabilidade geral do fenômeno migratório internacional. Em termos operativos, isso implica a formulação e implementação de políticas tais como:

- Colocar o tema da migração internacional na agenda hemisférica e global, com propósito de chegar a acordos satisfatórios para todas as partes;

- $\quad$ Subscrever e cumprir os preceitos derivados dos acordos internacionais sobre proteção dos direitos humanos dos migrantes e seus familiares;

- Lutar contra a "indústria" do tráfico de seres humanos e contra outros espúrios fenômenos semelhantes (racismo, xenofobia, discriminação trabalhista, etc.); 
- $\quad$ Reconhecer e valorizar as contribuições econômicas, sociais e culturais dos migrantes nas comunidades de destino;

- Mitigar os efeitos desagregadores da migração nas comunidades de origem, lembrando que o Estado e a sociedade de origem devem se esforçar para criar as condições mínimas de vida e de trabalho com o propósito de dissuadir ou desencorajar o impulso e as pressões em favor da opção migratória.

Em suma, trata-se de promover uma gestão migratória de alcance geral e integral, fundamentada na proteção dos direitos humanos mundialmente reconhecidos.

Complementarmente, outras áreas que precisam ser repensadas e redefinidas devem incluir: (a) facilitar as transferências de remessas enviadas pelos migrantes aos seus familiares - de modo geral, acredita-se que os serviços de intermediação financeira devem tornar-se mais econômicos, transparentes e confiáveis, e lembrando que se trata de recursos financeiros estimados em quase 40 bilhões de dólares anuais -, (b) estimular uma vinculação duradoura entre a sociedade de origem e a correspondente diáspora, fundamentada no principio do intercâmbio de conhecimentos, experiências e recursos, (c) agilizar o reconhecimento de documentos públicos (exemplos: títulos profissionais, vistos, certificados, etc.), (d) repensar a lógica e a práxis das políticas migratórias vigentes e, quando necessário, favorecer inovações, (e) criar e consolidar instituições nacionais e supra-nacionais especializadas em acompanhar de perto a evolução do fenômeno em questão e propor alternativas oportunamente.

Contudo, convém insistir que uma tarefa fundamental e iniludível das sociedades e Estados latino-americanos na atualidade é justamente oferecer condições de vida e de trabalho cada vez mais dignas, honrosas e satisfatórias para seus cidadãos. Normalmente as pessoas optam por migrar quando chegam à conclusão de que o país de origem não oferece condições básicas de bem-estar econômico, político e social. Avançar nas condições para que os cidadãos não precisem (ou sejam forçados) a ir embora do país é certamente a melhor opção possível. Afinal, se realmente a população é a principal riqueza de um país, 
parece evidente que a migração de talentos, de mentes e de braços representa uma perda - temporária ou definitiva - que dificilmente poderá ser compensada no futuro.

\section{Conclusão}

Inicialmente, parece importante reconhecer que a noção de migração implica o movimento de pessoas - isto é, seu deslocamento geográfico temporário ou definitivo. O conjunto de motivações ou incentivos que historicamente impulsionaram as migrações é bastante numeroso, incluindo, por exemplo: a aspiração de melhorar as condições de vida e de emprego, os deslocamentos forçosos para preservar a integridade física, as desigualdades nos níveis de desenvolvimento, as assimetrias na distribuição dos benefícios oferecidos pela economia internacional, as carências de capital humano e conhecimentos, a curiosidade, dentre outros. Note-se, ainda, que o termo migrante não se limita aos deslocamentos de trabalhadores e profissionais (qualificados ou não). Outros indivíduos, tais como refugiados, turistas, estudantes, etc., também podem ser estudados a partir daquela categoria. Tudo isso sem esquecer as sinergias reais ou potenciais que surgem entre os chamados pull e push effects, isto é, as pressões migratórias endógenas e exógenas geradas pelo mundo atual, tanto nas economias desenvolvidas como nas economias em desenvolvimento.

Os agudos problemas econômicos e sociais dos países em desenvolvimento têm incrementado significativamente a migração internacional com destino aos países mais desenvolvidos - isto é, no sentido Sul-Norte. De fato, o crescimento explosivo nos últimos anos tem convertido a migração internacional num dos principais tópicos de discussão no contexto geral do processo de desenvolvimento econômico e social, bem como na agenda internacional. Daí o seu vínculo com o campo da disciplina Relações Internacionais.

Note-se, por exemplo, que a América Latina e Caribe é a região do mundo com maior intensidade de migrações internacionais no sentido Sul-Norte especialmente com destino aos Estados Unidos e certos países europeus. O 
impacto socioeconômico, político, cultural e propriamente internacional deste fenômeno é sumamente relevante, tanto nos países de origem, quanto nos países de destino e de trânsito ou passagem dos migrantes internacionais. Assim, calcula-se que em 2003 as transferências financeiras recebidas na América Latina superaram os EUA\$38 bilhões - montante superior ao valor combinado do Investimento Estrangeiro Direto e da Assistência Oficial para o Desenvolvimento recebido pelos países do subcontinente. O México, o Brasil e a Colômbia foram os principais países receptores destas transferências (ver Tabela 2).

Certamente, trata-se também de um fenômeno complexo e polemico. Sabese que muitos países desenvolvidos, especialmente no caso de certos Estados europeus (Itália, Espanha, Alemanha, etc.), por diferentes motivos precisam de força de trabalho jovem e capacitada oriunda de países em desenvolvimento. Porém, devido às pressões políticas domésticas, não deixam de reforçar os controles aplicáveis ao ingresso, passagem, residência e emprego dos estrangeiros, criando situações que violentam a dignidade e os direitos humanos básicos. O impacto do fenômeno da migração internacional nas comunidades e nos países de origem também é controvertido, dado que em não poucas oportunidades tais experiências implicam a separação mais ou menos duradouras das famílias, a fuga de recursos humanos capacitados, e tensões sociais em geral.

Paralelamente, no marco geral do assim chamado processo de globalização é paradoxal que em um mundo cada vez mais conectado e interdependente, fundamentado na mobilidade de fatores de produção, capitais, comércio e investimento, a mobilidade das pessoas e especificamente da força de trabalho se depare com tantas restrições e proibições. Vários estudos e pesquisas constatam que em etapas anteriores da história da globalização os deslocamentos de população foram paralelos ao desenvolvimento de contatos e de fluxos entre diferentes sociedades e culturas. Tais estudos e pesquisas não deixam de questionar a aparente exclusão da migração internacional no debate sobre a atual fase de globalização, especialmente quando se trata dos grandes deslocamentos humanos no sentido Sul-Norte. Conseqüentemente, parece evidente que tais 
restrições migratórias colocam em debate as implicações éticas, políticas, econômicas e propriamente de política internacional da atual fase do assim chamado processo de globalização.

Agosto de 2005

\section{NOTAS}

${ }^{1}$ Note-se que tópicos específicos de pesquisa em relações internacionais sobre a questão da migração internacional desde América Latina e Caribe podem incluir: (a) causas e conseqüências das migrações internacionais latino-americanas e caribenhas, especialmente nas comunidades de origem dos migrantes; (b) políticas migratórias latino-americanas e de outros países (políticas migratórias comparativas); (c) correlações entre migração e desenvolvimento; (d) comunidades transnacionais como fenômeno "interméstico"; (e) custos, desafios e oportunidades da migração; (f) a questão da migração na formulação e implementação da política externa global dos países latino-americanos e caribenhos; (g) migração e preservação dos direitos humanos; $(\mathrm{h})$ facilitação e redução de custos - bem como uso produtivo - das transferências ou remessas de dinheiro enviadas pelos migrantes aos seus países de origem; dentre outros.

${ }^{2}$ A migração intra-regional ou entre países latino-americanos e caribenhos continua tendo certa relevância, especialmente nos movimentos transitórios, temporários ou fronteiriços. Tradicionalmente, a Argentina e a Venezuela, bem como a Costa Rica, o Panamá e o México foram importantes receptores de população latino-americana. Nos últimos anos, o Chile e o Brasil especificamente a cidade de São Paulo - também passaram a recepcionar trabalhadores oriundos de países vizinhos. Contudo, trata-se de fluxos migratórios relativamente pequenos ou médios, quando comparados ao fluxo migratório com destino aos Estados Unidos.

${ }^{3} \mathrm{O}$ fluxo fronteiriço entre os Estados Unidos e o México é antigo. Porém, a partir do decênio de 1970 deixou de ser temporário, oscilatório e intermitente, constituindo-se em fenômeno estrutural e de alta e crescente relevância para os povos e governos de ambos os países. Atualmente, aproximadamente 15 milhões de mexicanos vivem nos Estados Unidos, e 1,5 milhões de estadunidenses moram no México.

${ }^{4}$ Aproximadamente dois milhões de latino-americanos residem em países da Europa Ocidental, no Canadá, no Japão, na Austrália, em Israel e em outros países.

${ }^{5}$ Distinguir as diferenças entre as noções de "minoria" e "comunidade" de imigrantes também é pertinente. Em termos gerais, a noção de minoria implica que certos grupos étnicos radicados em um Estado receptor são segregados e excluídos tanto no mercado de trabalho e nas zonas de residência (guetos), como também nas atividades sociais, culturais e políticas. Em contraste, a noção de comunidade implica que os imigrantes e seus descentes são vistos como parte integral e legítima de uma sociedade culturalmente heterogênea.

${ }^{6} \mathrm{Com}$ aproximadamente 40 milhões de pessoas de origem hispânica, os Estados Unidos já são o quarto país com maior número de pessoas que falam espanhol no mundo - sendo superado apenas pelo México, pela Colômbia e pela Espanha. A comunidade hispânica estadunidense é mais numerosa que a população da Argentina. Assim, trata-se de um mercado consumidor cada vez mais expressivo naquele país.

\section{Bibliografia}

CEPAL (2002): Globalização e desenvolvimento, Santiago do Chile: Nações Unidas.

HELD, David e outros (1999): Global transformations/ Politics, Economics and Culture, Stanford: Stanford University Press.

PELLEGRINO, Adela (2003): "La migración internacional en América Latina y el Caribe: tendencias y perfiles de los migrantes", serie Población y Desarrollo 35, Santiago de Chile: CELADE e BID. 
SELA (2004): "Remesas de migrantes: ¿Una alternativa para América Latina y el Caribe?”, n 45, na internet: www.sela.org 